\title{
Pricing for irrigation water on Japanese paddy-fields: applicability of stochastic choice model
}

\author{
Y. Kunimitsu \\ Department of Rural Planning, \\ National Institute for Rural Engineering, Japan
}

\begin{abstract}
Water pricing attracts great public interest for efficient water use in the world. However, there have been few studies to analyze irrigation water value, in particular with respect to Japanese paddy-fields owing to the difficulty in achieving a precise measurement for water volume on site. This paper evaluates the water pricing value in Japanese rice production by a stochastic choice model similar to the contingent valuation method. The estimation results showed that i) the derived demand for irrigation water with regard to water pricing value is inelastic, ii) the water pricing value evaluated by farmers is not high enough to compensate for the full-costs of the water supply including renewal costs of irrigation facilities and running costs, and iii) the water pricing value was affected by rice price and unit harvest of rice production. Therefore, the bidding price of paddy-field irrigation water can be simulated by the stochastic choice model, although water pricing policy is not well accepted by farmers in Japan at present.

Keywords: profit function of rice production, contingent valuation method (CVM), Logit model, conjoint analysis, price elasticity.
\end{abstract}

\section{Introduction}

Water is quite limited and is one of the key resources for sustainable development of the world. For efficient use, water pricing has been discussed as an urgent policy issue in the World Water Forum. In the field of economics, Kan et al. [2], Wang and Lall [9] and Moore [6] analyzed the derived demand of irrigation water in semi-arid regions based on production and cost functions in 
dry fields. Smith and Roumasset [8] and Krulce et al. [3] simulated the allocation of drinking water with a linear programming model. These studies showed that the price elasticity of water is relatively low, indicating that water is an essential factor for economies. The value of water quality has also been measured by the hedonic price method (Mendelsohn et al. [5]) and contingent valuation method (CVM) (Carson and Mitchell [1], Poe and Bishop [7]). However, few empirical studies have been conducted on irrigation water for paddy-fields in the Asian monsoon region as well as Japan because of a lack of data on the volume of irrigation water, which fluctuates by seasons.

This study aims to analyze and evaluate irrigation water for paddy-fields as a shadow price of water in rice production, the main agricultural product of the Asian monsoon regions. A stochastic choice model, similar to CVM, is employed based on micro data of individual farmers.

\section{Methodology}

\subsection{Optimal profit for farmers}

Given that farmers maximize their profit of rice production under the technical constraints of production function, the log linear type of profit function can be defined as follows.

$$
\begin{aligned}
& \ln (R)=a+b \ln (A)+c \ln (W)+d \ln (P)+e \ln \left(P_{V}\right)+\varepsilon \\
& \quad=f\left(A, W, P, P_{V}\right)+\varepsilon=\mathbf{X} \boldsymbol{\beta}+\varepsilon
\end{aligned}
$$

Here, $R$ is a profit of an individual farmer, $A$ is the farm management area, $W$ is the quantity of irrigation water, $P$ is the price of rice, and $P_{V}$ is the price of the conjunction input factors, such as labor, agricultural machinery, fertilizers and pesticides. The variable $\varepsilon$ represents technological gaps between farmers, relating to skills for efficient production, knowledge for avoiding serious damage from disease and natural disaster. $A$ and $W$ exist in Eq. (1), unlike with other input factors substituted by $P_{V}$ according to the first order condition, because farmland and irrigation water are semi-fixed inputs which farmers can hardly optimize under a regulated market. $\mathbf{X}$ is the vector of explanatory variables.

The term $\varepsilon$ in Eq. (1) is treated as error-term in the conventional production function approach, but is an essential variable for describing farmers' decision making. Hence, micro data on farmer responses were employed to estimate the above equations, treating $\varepsilon$ specifically using hypothetical situations on changes in water quantities, $\triangle W$ (Kunimitsu [4]).

\subsection{Preservation fund for renovation of irrigation facilities (Model 1)}

Hypothetical situations set for farmers were payment, $B$, for a preservation fund of irrigation facilities which affects the volume of usable water. Farmers were asked the following questions for Model 1.

"If you do not invest in the renewal of irrigation facilities built in this area, you will not be able to obtain irrigation water from the river for your paddyfields with the collapse of facilities in the future. To avoid such a collapse 
and prepare for future renewal construction, we are planning a preservation fund from farmers. Would you agree to pay $B_{1}$ into a planning fund? "

Here, $B_{I}$ was randomly changed for each farmer to obtain different reactions. The double bounded questionnaire method was used by asking a second question to improve the estimation efficiency. The second higher price, $B_{2 H}$, was asked to farmers agreed with the first question, and the second lower price, $B_{2 L}$, was asked to farmers refused the first question. Both the first and second questions were made as dichotomous choices with 'yes-no' answers to duplicate the real decisions of farmers.

Farmers would agree, if the following condition were satisfied.

$$
\ln (B) \leq \ln (\Delta R)=\ln \left(R_{0}-R_{1}\right)=f\left(A, W_{0}, P, P_{V}\right)+\varepsilon=\mathbf{X} \boldsymbol{\beta}+\varepsilon
$$

Here, $W_{0}$ is the initial volume of irrigation water, and $R_{0}$ is profit at initial condition. $R_{I}$ is profit of rain-fed production under collapse of irrigation facilities, and supposed to be zero even after obtaining some products. $B$ represents the proposed payment of $B_{1}, B_{2 H}$ and $B_{2 L}$.

If $\varepsilon$ is i.i.d. and described by the cumulative probability function $G$ representing logistic distribution, the acceptance probability of farmers can be defined as following logit model.

(First answer is 'yes' followed by second answer 'yes')

$$
\operatorname{Pr}\left\{\ln (\Delta R)>\ln \left(B_{2 H}\right)\right\}=1-G\left\{\mathbf{X} \boldsymbol{\beta}+\gamma \ln \left(B_{2 H}\right)\right\}=\frac{\exp \left\{\mathbf{X} \boldsymbol{\beta}+\gamma \ln \left(B_{2 H}\right)\right\}}{1+\exp \left\{\mathbf{X} \boldsymbol{\beta}+\gamma \ln \left(B_{2 H}\right)\right\}},
$$

(First answer is 'yes' followed by second answer 'no')

$$
\operatorname{Pr}\left\{\ln \left(B_{2 H}\right) \geq \ln (\Delta R) \geq \ln \left(B_{1}\right)\right\}=\frac{1}{1+\exp \left\{\mathbf{X} \boldsymbol{\beta}+\gamma \ln \left(B_{2 H}\right)\right\}}-\frac{1}{1+\exp \left\{\mathbf{X} \boldsymbol{\beta}+\gamma \ln \left(B_{1}\right)\right\}},
$$

(First answer is 'no' followed by second answer 'yes')

$$
\operatorname{Pr}\left\{\ln \left(B_{1}\right) \geq \ln (\Delta R) \geq \ln \left(B_{2 L}\right)\right\}=\frac{1}{1+\exp \left\{\mathbf{X} \boldsymbol{\beta}+\gamma \ln \left(B_{1}\right)\right\}}-\frac{1}{1+\exp \left\{\mathbf{X} \boldsymbol{\beta}+\gamma \ln \left(B_{2 L}\right)\right\}},
$$

(First answer is 'no' followed by second answer 'no')

$$
\operatorname{Pr}\left\{\ln \left(B_{2 L}\right) \geq \ln (\Delta R)\right\}=\frac{1}{1+\exp \left\{\mathbf{X \beta}+\gamma \ln \left(B_{2 L}\right)\right\}}
$$

Here, $\gamma<0$.

\subsection{Conjoint analysis on paddy-field renting (Model 2)}

Questions asked to farmers were,

"Suppose you rent a paddy-field from other farmers and the field has average soil fertility and geographical conditions, but the rental rate, quantity of water, drainage conditions and location are different. Choose the most preferable field among the alternative options."

Options were,

Number: quantity of water, rental rates, drainage condition, distance,

1: $W_{0}-\triangle W_{1}, B_{1}, D_{1}, L_{1}$,

2: $W_{0}-\triangle W_{2}, B_{2}, D_{2}, L_{2}$,

3: $W_{0}-\triangle W_{3}, B_{3}, D_{3}, L_{3}$,

4: above conditions are all less preferable. 
Quantities of water $\left(W_{0}-\Delta W_{i}\right)$ in the i-th choice were half, the same and 1.2 times larger when compared to the status quo. Rental rates $\left(B_{i}\right)$ were 5000, $15000,25000,35000$ and 45000 yen/ 0.1 ha. Drainage conditions $\left(D_{i}\right)$ consisted of two levels, good and bad in drainage of surface water, and location of the field $\left(L_{i}\right)$ was within $2 \mathrm{~km}$ or more than $2 \mathrm{~km}$. The total number of combinations were $3 * 5 * 2 * 2=60$. In order to make the choice simple, 15 combination sets were selected by using the diagonal design. Five groups, including an avoidance choice and three field conditions out of the 15 sets, were used for each type of questionnaire.

Profit for each option (i) is

$$
\ln \left(R_{i}\right)=f\left(A, W_{0}-\Delta W_{i}, P, P_{V}, D_{i}, L_{i}\right)+\varepsilon-\ln \left(B_{i}\right)=\mathbf{X}_{\mathbf{i}} \boldsymbol{\beta}-\ln \left(B_{i}\right)+\varepsilon
$$

If $\varepsilon$ is i.i.d. and described by the cumulative probability function, the choice of farmers for the $\mathrm{j}$-th field can be defined as following conditional logit model.

$$
\operatorname{Pr}\left\{\ln \left(R_{j}\right) \geq \ln \left(R_{i}\right)\right\}=\frac{\exp \left\{\mathbf{X}_{\mathbf{j}} \boldsymbol{\beta}+\gamma \ln \left(B_{j}\right)\right\}}{1+\sum_{i} \exp \left\{\mathbf{X}_{\mathbf{i}} \boldsymbol{\beta}+\gamma \ln \left(B_{i}\right)\right\}}, \quad i, j \in I, i \neq j
$$

Here, $\gamma<0$, and $I$ consists of choice sets within each group.

\subsection{Pricing for irrigation water}

Considering the democratic decision making scheme under Model 1: pricing for irrigation water can be defined as the value to which half of farmers willingly pay. That is, water pricing value, $P_{W}$, is calculated as the median value defined by $G\left\{\overline{\mathbf{X}} \boldsymbol{\beta}+\gamma \ln \left(B^{*}\right)\right\}=0.5$. Then,

$$
P_{W}=B^{*}=\exp \{-\overline{\mathbf{X}} \boldsymbol{\beta} / \gamma\}
$$

In terms of Model 2 in Eq. (5), the marginal profitability, $M R_{W}$, can be defined by the conditions making profit constant. As the whole differential of Eq. (4) is set as zero, $d R=0$, then,

$$
M R_{W}=\frac{\partial B}{\partial W}=-\frac{\alpha}{\gamma} \frac{B}{W}
$$

Here, $\alpha$ and $\gamma$ are estimated coefficients of $W$ and $B$, respectively. The certain value of water, $P_{W}$, can be calculated from $M R_{w}$ at the present volume of $W$ with setting $B$ as the average actual rental rate published in the Cost Research of Rice Production (MAFF).

The demand elasticity of water with regard to water pricing value is,

$$
\eta=\frac{\partial W}{W} / \frac{\partial B}{B}=-\frac{\gamma}{\alpha}
$$

\subsection{Data}

Data were collected from three sites by questionnaires in 2002 and 2003 (Table 1). Questions for Model 2 were included in questionnaire sheets only in Site 3. The data for each site was collected by mail or direct distribution of questionnaires in cooperation with the Ministry of Agriculture, Forestry and Fishery (MAFF) and the Farmland Consolidation District (FCD) which was established in each site. FCD worked for operation and management of the 
irrigation facilities with a budget collected from farmers, so that they know farmers quite well.

In Sites 1, 2 and 3 beneficial areas were 5000 ha, 3000 ha and 6000 ha of paddy-fields, respectively, and the numbers of farmers that used the consecutive irrigation facilities were 5159, 6444 and 5112, respectively. These three sites were located in representative rice production areas of Japan. All paddy-fields in the three sites used irrigation water from the river through an upstream sluice dam and irrigation canals. If there were no such facilities, farmers could not use the irrigation water and they had to adopt rain-fed production.

Table 1: $\quad$ Results of the questionnaires.

\begin{tabular}{lccc}
\hline & $\begin{array}{c}\text { MoriokaNanbu } \\
(\text { Site 1) }\end{array}$ & $\begin{array}{c}\text { Oosato } \\
\text { (Site 2) }\end{array}$ & $\begin{array}{c}\text { ShinanogawaSagan } \\
\text { (Site 3) }\end{array}$ \\
\hline $\begin{array}{l}\text { Date of Research } \\
\text { No. distributed }\end{array}$ & $03 / 2002$ & $10 / 2003$ & $12 / 2003$ \\
$\begin{array}{l}\text { Distribution } \\
\text { Method }\end{array}$ & 1,000 & 5,765 & 4,798 \\
& Sampling & All Farmers & $\begin{array}{c}\text { All Farmers } \\
\text { Via Mail } \\
\text { (+2nd request) }\end{array}$ \\
No. collected & 393 & Hand out & 2,404 \\
$\quad$ Collection Rate & 0.39 & 4,050 & 0.50 \\
Effective Answers & 254 & 0.70 & 1,133 \\
$\quad$ Effective Rate & 0.65 & 1,724 & 0.47 \\
\hline Estimation case that used the site data & 0.43 & \multicolumn{2}{c}{} \\
$\quad$ Model 1 & $\checkmark$ & $\checkmark$ & $\checkmark$ \\
$\quad$ Model 2 & & \multicolumn{2}{c}{} \\
\hline
\end{tabular}

\section{Results}

\subsection{Estimations}

Tables 2 and 3 are the estimation results of Model 1 and Model 2, respectively. In estimations, zone dummies were used as proxy of $W_{0}$ in Model 1 , because the volume of irrigation water is difficult for measurement. Irrigation water is about the same for all paddies inside the zone, though there are differences in volume between zones. $P_{V}$ consisting of wages, price of agricultural machinery and pesticides and fertilizers were neglected, because there was no variability between farmers within each site. Also, $P$ was a given factor and constant for each farmer, but the expected prices of farmers were different and used for $P$ instead of the market price of rice.

In both tables, coefficients of proposed rates $B$ were negative and highly significant as compared by t-statistics, corresponding to the economic theory.

Model 1 shows that higher rice price $P$ and unit harvest $q$ bring about higher agreement for payment to the preservation fund, but management scale $A$ shared 
insignificant coefficients because of a possible offset between economies of scale and diminishing returns of farmland areas.

Model 2 shows that more water brought a greater profit and consequently higher agreement among farmers. Also, more water meant better drainage conditions and neighboring field raises profits.

Table 2: $\quad$ Estimations of Eq. (3) for Model 1.

\begin{tabular}{lccr}
\hline \multicolumn{1}{c}{ Explanatories } & Site 1 & Site 2 & \multicolumn{1}{c}{ Site 3 } \\
\cline { 2 - 4 } & Coeff. (t-stat.) & Coeff. (t-stat.) & Coeff. (t-stat.) \\
\hline Constant & $-4.110(-0.7)$ & $-6.089(-0.8)$ & $1.111(0.1)$ \\
Proposed Rate, $B$ & $-1.007\left(-12.5^{* *}\right)$ & $-1.064\left(-23.4^{* *}\right)$ & $-1.012\left(-22.7^{* *}\right)$ \\
Rice Price, $P$ & - & $0.748\left(2.1^{* *}\right)$ & $0.522(1.0)$ \\
Unit Harvest, $q$ & $1.909\left(2.1^{* *}\right)$ & $0.948(0.8)$ & $0.168(0.2)$ \\
Management Area, $A$ & $0.461(1.5)$ & $0.131(0.9)$ & $0.264(1.4)$ \\
Aggressive Farmer & $-0.788\left(-2.2^{* *}\right)$ & $-0.124(-0.4)$ & - \\
Age & $-0.571\left(-2.2^{* *}\right)$ & $0.013\left(1.8^{*}\right)$ & - \\
\hline Water in upstream, $W_{I}$ & - & - & $-0.979\left(-2.8^{* *}\right)$ \\
Water in downstream, $W_{2}$ & - & $0.445\left(2.3^{* *}\right)$ & $0.743\left(1.7^{*}\right)$ \\
Water in downstream, $W_{3}$ & - & $0.405\left(1.8^{*}\right)$ & - \\
Water in special area, $W_{4}$ & - & $-0.462\left(-1.8^{*}\right)$ & - \\
\hline No. of data (farmers) & 254 & 805 & 463 \\
Log-likelihood & -357.9 & -1005.0 & -686.2 \\
AIC & 732 & 2,026 & 1,388 \\
Correct Pred. Rate & 0.421 & 0.475 & 0.406 \\
\hline Note: 1. “** $5 \%$ signficance, & $10 \%$ signicance & &
\end{tabular}

Note: 1. “**” 5\% significance, “*” 10\% significance

Table 3: $\quad$ Estimations of Eq. (4) for Model 2 in Site 3.

\begin{tabular}{lrr}
\hline \multicolumn{1}{c}{ Explanatories } & \multicolumn{1}{c}{ Linear } & \multicolumn{1}{c}{ Log linear } \\
\cline { 2 - 3 } & \multicolumn{1}{c}{ Coeff. (t-stat.) } & \multicolumn{1}{c}{ Coeff. (t-stat.) } \\
\hline Water, $W-\triangle W$ & $0.715\left(6.3^{* *}\right)$ & $9.43 \mathrm{E}-03\left(6.3^{* *}\right)$ \\
Rental rate, $B$ & $-0.286\left(-3.7^{* *}\right)$ & $-2.64 \mathrm{E}-05\left(-6.2^{* *}\right)$ \\
Drainage condition, $D$ & $0.981\left(9.3^{* *}\right)$ & $1.063\left(10.2^{* *}\right)$ \\
Location, $L$ & $0.483\left(5.4^{* *}\right)$ & $0.504\left(5.7^{* *}\right)$ \\
\hline no. of data & 831 & 831 \\
Log-likelihood & -839 & -830 \\
MacFadden R2 & 1.92 & 1.91 \\
\hline
\end{tabular}

Note: 1. "**" 5\% significance, "*" $10 \%$ significance

2. $\mathrm{L}=1$; distance was less than $2 \mathrm{~km}$, and $\mathrm{L}=0$; other wise. 


\subsection{Pricing value for irrigation water}

Figure 1 shows marginal value of water calculated from Model 2. The marginal profitability of water shown by the inclination of the curve decreased with an increase in water volume. This indicates diminishing returns of water productivity in rice production. The marginal value of water at $100 \%$ was about two times higher than at $50 \%$.

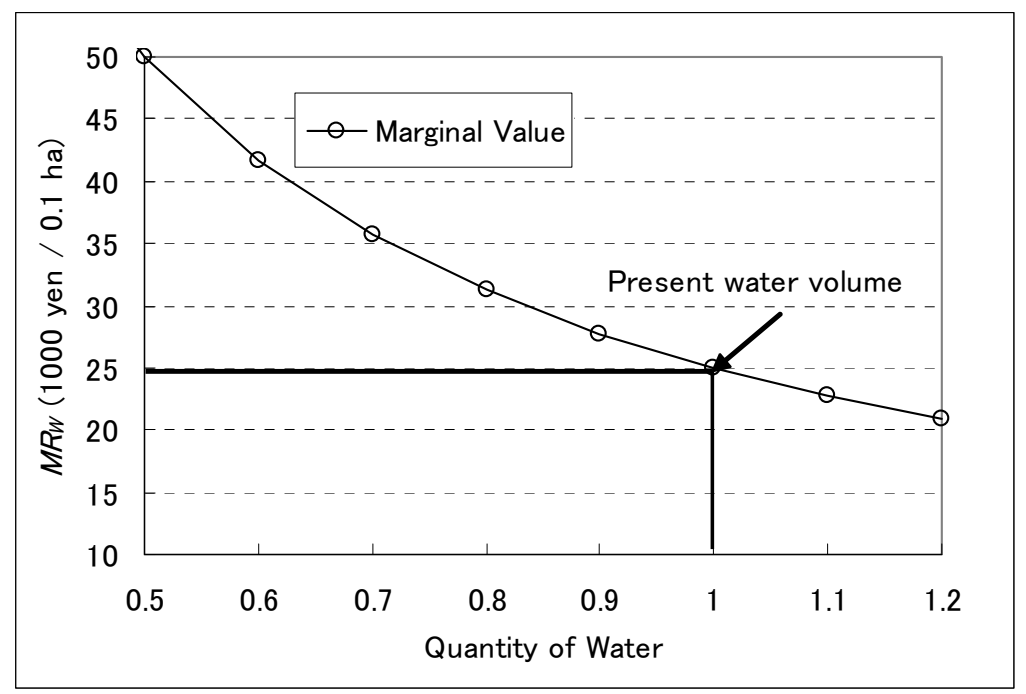

Figure 1: $\quad$ Marginal value of irritation water (Model 2).

Table 4: $\quad$ Price of irrigation water and comparison with costs.

\begin{tabular}{lrrrr}
\hline & \multicolumn{3}{c}{ Model 1 } & \multicolumn{1}{c}{ Model 2 } \\
\cline { 2 - 5 } \multicolumn{1}{c}{ Items } & \multicolumn{1}{c}{ Site1 } & \multicolumn{1}{c}{ Site 2 } & \multicolumn{1}{c}{ Site 3 } & \multicolumn{1}{c}{ Site 3 } \\
\hline Marginal value, $M R_{W}$ & \multicolumn{1}{c}{-} & \multicolumn{1}{c}{ - } & \multicolumn{1}{c}{ (25,000 -20,800 } \\
$P_{W}$ & 2,396 & 1,258 & 1,781 & 25,000 \\
\hline Costs (Total) & 16,953 & 52,560 & 43,209 & 43,209 \\
Construction costs & 13,253 & 49,560 & 38,709 & 38,709 \\
Running costs of LCDs & 3,700 & $2,500-3,000$ & 4,500 & 4,500 \\
\hline
\end{tabular}

Note: 1. $P_{W}$ was calculated from Eqs. (5) and (6), construction costs were calculated from annual depreciation values when irrigation facilities would have been reconstructed.

2. Running costs of LDCs are for main irrigation facilities, excluding small ones. 
The demand elasticity with regard to water value was 0.4 , indicating an inelastic demand of water, the same as results of production functions in previous studies. In other words, changes in water price have a limited effect on the change in irrigation water volume used for agriculture.

Table 4 shows comparisons of water pricing values. The water value $\left(P_{W}\right)$ by Model 2 is higher than that by Model 1 . In terms of a preservation fund for Model 1, farmers probably expected subsidies from the government according to the Land Improvement Law in Japan, evaluating water value as unimportant.

The value of $P_{W}$ in Site 1 is the highest among other sites. In Site 1, the FCD has collected an extra fee from farmers to keep the upstream forest as a water source and for future renovation of irrigation facilities. This effort by FCD probably helps farmers consider future preservation with higher payments.

Interestingly, the estimated $P_{W}$ was lower than the total annual costs including reconstruction and running costs. The demand-side evaluations of water shown by $P_{W}$ cannot compensate for the total costs, so that introduction of a water pricing mechanism into rice production is considered unacceptable by farmers. In addition, water pricing becomes more serious under the depression of rice price $P$ in the recent market, because depression of the price of rice leads to a lack of agreement for the proposed rate in the hypothetical situation.

\section{Summary and conclusion}

The shadow price of irrigation water as water pricing value was estimated on Japanese paddies by the stochastic choice models is similar to CVM in terms of preservation fund and renting under conjoint conditions.

The results showed that the derived demand for irrigation water with regard to water-pricing value is inelastic. Secondly, the water value evaluated by farmers is not high enough to compensate for the full cost of water supply including reconstruction and running costs of irrigation facilities. Thirdly, the water value was affected by rice price expectations of farmers and unit harvest levels of rice production.

From the above results, we can conclude that a water pricing policy is less powerful to coordinate water use in Japanese paddy-fields. In practice, the price of rice does not include irrigation costs, especially when subsidies are considered. Most of farmers cannot make a profit under a water pricing scheme given the present rice price. Nevertheless, the method employed here is useful to find causative factors and to discuss a water-pricing policy scheme.

\section{References}

[1] Carson, R.T. and Mitchell, R.C., The value of clean water: the public's willingness to pay for boatable, fishable, and swimmable quality water, Water Resources Research, 29(7), pp. 2445-54, 1993.

[2] Kan, I., Schwabe, K. A. and Knapp, K.C., Microeconomics of Irrigation with Saline Water, J. of Agri. and Resource Econ., 27(1), pp. 16-39, 2002. 
[3] Krulce, D. L., Roumasset, J.A. and Wilson, T., Optimal Management of a Renewable and Replaceable Resource: The Case of Coastal Groundwater, Ameri. J. of Agri. Econ., 79, pp. 1218-1228, 1998.

[4] Kunimitsu, Y. Effects of Socio-institutional and Emotional Factors on Japanese Farmland Rental Transactions, J. of Agri. \& Applied Econ., 38(1), pp. 33-46, 2006.

[5] Mendelsohn, R., Hellerstein, D., Hugenin, M., Unsworth, R. and Brazee, R., Measuring hazardous waste damages with panel models, J. of Environmental Econ. and Management, 22, pp. 259-71, 1992.

[6] Moore, M. R. Estimating Irrigators' Ability to Pay for Reclamation Water, Land Econ., 75(4), pp. 562-578, 1999.

[7] Poe, G.L. and Bishop, R.C., Valuing the incremental benefits of groundwater protection when exposure levels are known, Environmental and Resource Econ., 13(3), pp. 341-367, 1999.

[8] Smith, R. B.W. and Roumasset, J., Constrained conjunctive-use for endogenously separable water markets: managing the Waihole-Waikane aqueduct, Agricultural Econ., 24, pp. 61-71, 2002.

[9] Wang, H. and Lall, S., Valuing water for Chinese industries: a marginal productivity analysis, Applied Econ., 34, pp. 759-765, 2002. 